\title{
Gefapixant in two randomised dose-escalation studies in chronic cough
}

\author{
Jaclyn A. Smith (1) ${ }^{1}$, Michael M. Kitt ${ }^{2}$, Peter Butera ${ }^{2}$, Steven A. Smith², \\ Yuping $\mathrm{Li}^{3}$, Zhi Jin $\mathrm{Xu}^{2}$, Kimberley Holt ${ }^{1}$, Shilpi Sen ${ }^{1}$, Mandel R. Sher ${ }^{4}$ and \\ Anthony P. Ford ${ }^{2}$
}

Affiliations: ${ }^{1}$ University of Manchester and Manchester Academic Health Science Centre, Manchester University NHS Foundation Trust, Manchester, UK. ${ }^{2}$ Merck \& Co., Inc., Kenilworth, NJ, USA. ${ }^{3}$ GetStat Solutions, LLC, Palo Alto, CA, USA. ${ }^{4}$ Center for Cough, Largo, FL, USA.

Correspondence: Jaclyn A. Smith, Division of Infection, Immunity and Respiratory Medicine, University of Manchester, Manchester University NHS Foundation Trust, Level 2, Education and Research Centre, Wythenshawe Hospital, Manchester M23 9LT, UK. E-mail: jacky.smithamanchester.ac.uk

@ERSpublications

Patients with refractory chronic cough had significant reductions in coughing with lower doses of gefapixant than previously evaluated demonstrating efficacy and improved tolerability http://bit.ly/ $2 \mathrm{Rg} 3 \mathrm{q} 2 \mathrm{t}$

Cite this article as: Smith JA, Kitt MM, Butera P, et al. Gefapixant in two randomised dose-escalation studies in chronic cough. Eur Respir J 2020; 55: 1901615 [https://doi.org/10.1183/13993003.01615-2019].

\section{ABSTRACT}

Background and objectives: Gefapixant has previously demonstrated efficacy in the treatment of refractory chronic cough at a high daily dose. The current investigations explore efficacy and tolerability of gefapixant, a P2X3 receptor antagonist, for the treatment of chronic cough using a dose-escalation approach.

Materials and methods: Two randomised, double-blind, placebo-controlled, crossover, dose-escalation studies recruited participants with refractory chronic cough. Patients were assigned to receive ascending doses of gefapixant (study 1: 50-200 mg, study 2: 7.5-50 mg) or placebo for 16 days, then crossed-over after washout. The primary end-point was awake cough frequency assessed using a 24-h ambulatory cough monitor at baseline and on day 4 of each dose. Patient-reported outcomes included a cough severity visual analogue scale and the cough severity diary.

Results: In clinical studies, gefapixant doses $\geqslant 30 \mathrm{mg}$ produced maximal improvements in cough frequency compared with placebo $(\mathrm{p}<0.05)$; reported cough severity measures improved at similar doses. Taste disturbance exhibited a different relationship with dose, apparently maximal at doses $\geqslant 150 \mathrm{mg}$.

Conclusions: P2X3 antagonism with gefapixant demonstrates anti-tussive efficacy and improved tolerability at lower doses than previously investigated. Studies of longer duration are warranted.

This article has supplementary material available from erj.ersjournals.com

This study is registered at www.clinicaltrials.gov with identifier number NCT02349425 and on the EU Clinical Trials Register (EudraCT Number: 2015-000474-35) Data availability: the data sharing policy of Merck Sharp and Dohme Corp. (a subsidiary of Merck and Co., Inc., Kenilworth, NJ, USA), including restrictions, is available at http:// engagezone.msd.com/ds_documentation.php. Requests for access to the clinical study data can be submitted through the EngageZone site or via email to dataaccess@merck.com.

Received: 13 Aug 2019 | Accepted after revision: 19 Dec 2019

Copyright OERS 2020 


\section{Introduction}

Effective treatments for cough are a significant unmet clinical need, with no new therapies approved in $>50$ years. Billions of dollars are spent annually in the United States alone on over-the-counter cough and cold medicines [1] despite a lack of evidence to support their efficacy [2], concerns about abuse potential [3] and risk of harm in overdose [4,5]. The majority of these purchases are prompted by acute viral infections, where coughing usually remits spontaneously, but patients with chronic cough may suffer for many years, sometimes coughing $>100$ times per hour during waking hours [6], with very limited treatment options. Therefore, refractory chronic cough can have a marked impact on quality of life [7].

Preclinical evidence suggests roles for afferent vagal $\mathrm{C}$ (chemosensing) and $\mathrm{A} \delta$ (mechanosensing) neurones in activating the cough reflex. Purinergic receptors, including P2X3 ATP-gated cation channels, are expressed in these sensory neurones [8]. When inhaled, ATP evokes coughing in healthy controls, asthma, COPD and chronic cough patients [9-11], and in animal studies inhaled ATP heightens cough responses to other irritants $[12,13]$. Endogenous ATP, released due to inflammation or shearing forces or smooth muscle contraction in airways may be an important mechanism for patients with refractory chronic cough, which suggests that $\mathrm{P} 2 \mathrm{X} 3$-containing receptors may be a target in this condition.

A recent study evaluating a first-in-class P2X3 receptor antagonist, gefapixant (MK-7264; formerly known as AF-219) in refractory chronic cough patients, revealed a $75 \%$ reduction in daytime cough frequency compared to placebo, accompanied by striking improvements in patient-reported outcomes [14]. To definitively assess the anti-tussive potential of gefapixant in the initial proof-of-concept study, a high dose (600 mg twice daily) was selected [14]. However, coincident with the efficacy observed, all patients reported altered taste acuity (hypogeusia/dysgeusia), thought to be related to the inhibitory effect of gefapixant at the $\mathrm{P} 2 \mathrm{X} 2 / 3$ receptor on gustatory afferents.

The aims of the current studies were to evaluate the dose response of gefapixant in reducing awake objective cough frequency and to identify tolerable doses through the evaluation of low- and high-dose cohorts.

\section{Materials and methods}

This study (sponsor protocol 010; Clinical Trials Registry NCT02349425) was conducted in accordance with principles of good clinical practice. Local institutional review boards approved the study and all patients provided written informed consent. The study was initiated in March 2015 and completed in February 2016

\section{Study design and participants}

Two randomised, double-blind, placebo-controlled, two-period crossover, dose-escalation studies (figure 1a) at 12 sites in the USA, recruited participants with chronic cough ( $\geqslant 1$ year) that had undergone treatment trials and investigations to exclude potential underlying causes [15]. A cough severity visual analogue score (VAS) $\geqslant 40 \mathrm{~mm}$ was required at screening. Both studies consisted of two 16-day treatment periods with either 3-7-day (study 1) or 14-21-day (study 2) washout periods.

We excluded current or recent smokers ( $<6$ months' abstinence), those with $>20$ pack-year smoking history, a forced expiratory volume in $1 \mathrm{~s} /$ forced vital capacity ratio $<60 \%$ or a history of upper respiratory tract infection or significant change in pulmonary status within 4 weeks. In addition, patients on therapies that could modify cough and those with a history of renal disease or urolithiasis were excluded.

\section{Randomisation, blinding and dosing}

Patients were randomly assigned to receive gefapixant or placebo tablets twice daily (1:1) for 16 days and then crossed-over to the alternative treatment following the washout period. Placebo tablets matched active treatment tablets to maintain blinding. Randomisation was performed using an interactive voice response system (IVRS). Subjects and personnel involved with the conduct and interpretation of the study were blinded to treatment codes. Unblinding was done through IVRS by the medical monitor upon contact by the investigator. Study 1 investigated four twice-daily dose levels of gefapixant (50, 100, 150 and $200 \mathrm{mg}$ ), then study 2 investigated a lower range of four twice-daily dose levels (7.5, 15, 30 and $50 \mathrm{mg}$ ); the dose escalated every 4 days. Patients participating in study 1 were permitted to enrol in study 2 . A modified gefapixant formulation (or matching placebo) was used in study 2, allowing concomitant use of antacids (prohibited in study 1). The modified formulation was not a changed molecular structure, but rather the tablets were formulated with a small quantity of citric acid, serving as an acidulent, in order to maintain local acidity desirable for optimal dissolution. Such a modification to the tablet allowed inclusion of cough subjects taking antacids (e.g. proton pump inhibitors), who may otherwise have received reduced exposures to gefapixant [16]. 
a)
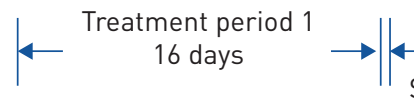

Washout Study 1: 3-7 days $\rightarrow$
Treatment period 2 16 days
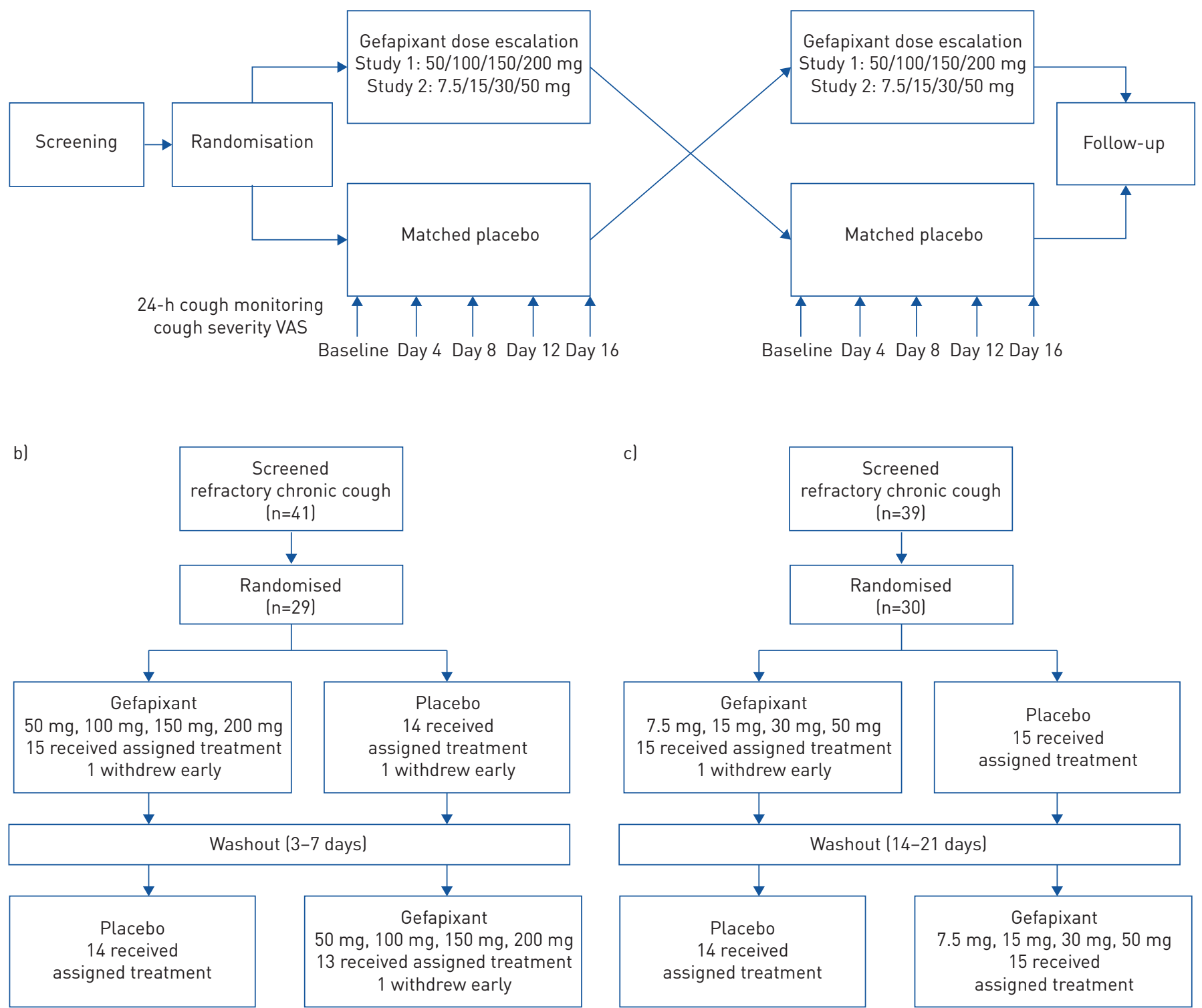

c)
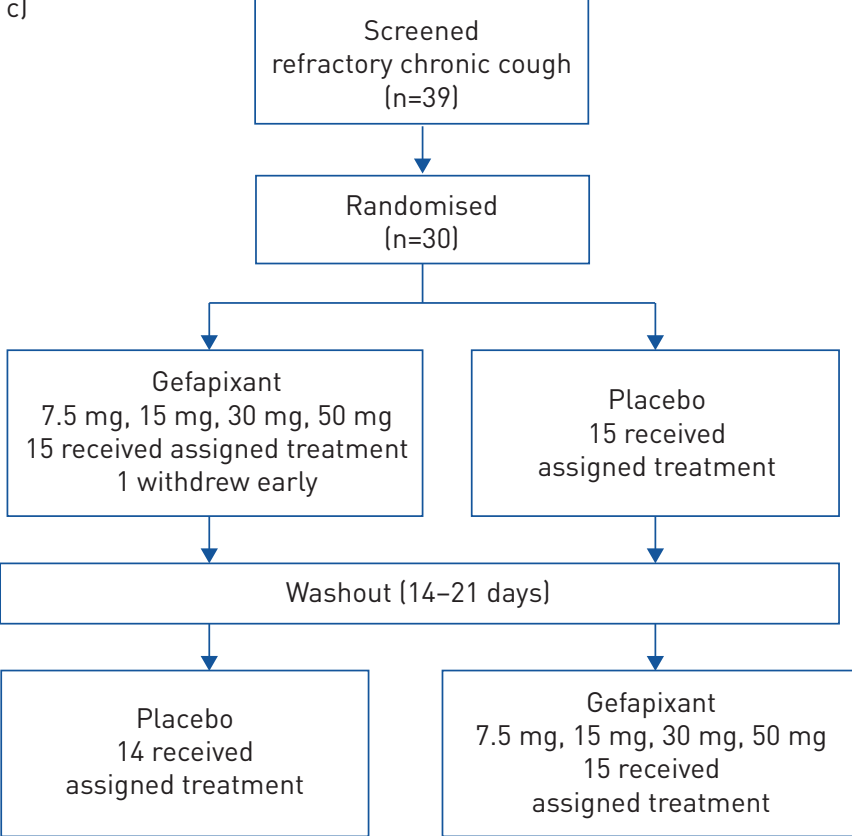

FIGURE 1 Study design, end-points and numbers of patients screened, enrolled and completing the studies. a) Both studies used a randomised double-blind placebo-controlled crossover design, with each dose of gefapixant/matched placebo administered twice daily for 4 days. Objective ambulatory cough frequency monitoring and cough severity visual analogue scales (VAS) were completed at baseline and on the fourth treatment day of each dose. b) Consort diagram for study 1. Three patients withdrew early: one patient withdrew due to ageusia, dyspepsia, oral paraesthesia and vertigo while taking gefapixant $50 \mathrm{mg}$; one developed a urinary tract infection associated with dehydration and acute renal failure while taking gefapixant $50 \mathrm{mg}$; and one withdrew due to symptoms of gastro-oesophageal reflux disease while taking placebo. c) Consort diagram for study 2 . One patient withdrew due to a jaw abscess and sinusitis while taking gefapixant $50 \mathrm{mg}$.

Procedures and outcome measures

The primary end-point was awake cough frequency objectively assessed at baseline and on day 4 of each dose level, using a 24-h ambulatory cough recorder (VitaloJAKTM; Vitalograph Ltd, Buckingham, UK). Patient-reported outcomes were 1) a cough severity 100-mm VAS, contemporaneous with the cough monitoring; 2) the cough severity diary [17], completed daily; and 3) cough-specific quality of life assessed using the Leicester Cough Questionnaire (LCQ) [18], completed at baseline and day 16 of the treatment periods; higher scores indicated better quality of life. Patient safety was assessed by recording adverse events, performing physical examinations, monitoring vital signs, ECGs and blood and urine analyses. 


\section{Statistical analysis}

Mixed model repeated measures analysis of variance (SAS version 9.3; SAS Institute Inc., Cary, NC, USA) assessed the change from baseline in awake cough frequency based on log-transformed data. Patient-reported measures were assessed using similar models. 12 patients per treatment sequence (gefapixant first versus placebo first) was estimated to provide $80 \%$ power to detect an average treatment effect of 0.65 (log-transformed data).

\section{Results}

\section{Participants}

59 patients were randomised; 29 in study 1 and 30 in study 2 with 18 subjects participating in both studies (figure $1 \mathrm{~b}$ and $\mathrm{c}$ ). Patients enrolled were primarily female (83\%), mean age 63 years (range $47-76$ years) and had cough durations ranging from 1.4 to 55.3 years (table 1). Four subjects terminated the study drug early due to adverse events: three in study 1 and one in study 2; only one termination was due to taste disturbance.

\section{Outcome measures}

All end-points for both studies are summarised in table 2. Baseline measures were similar for all treatment periods across all end-points, and there were no significant period or sequence effects in the analyses.

\section{Cough frequency}

The mixed-model repeated measures ANOVA suggested that all four doses of gefapixant evaluated in study 1 (50-200 mg) resulted in equivalent, statistically significant improvements in awake cough frequency compared with placebo (figure 2a); percentage change for gefapixant over placebo ranged from mean $(95 \% \mathrm{CI})-41.2 \%(-59.3--15.1 \%)$ at $50 \mathrm{mg}$ to $-57.1 \%(-73.4--30.8 \%)$ at $200 \mathrm{mg}$. In contrast, a dose-efficacy relationship was observed in study 2 (figure $2 \mathrm{~b}$ ); percentage change for gefapixant over placebo was $-14.7 \%(-35.3-12.5 \%)$ at $7.5 \mathrm{mg},-25.2 \%(-42.0--3.4 \%)$ at $15 \mathrm{mg},-37.1 \%(-57.3--7.4 \%)$ at $30 \mathrm{mg}$ and $-55.9 \%(-71.9--30.8 \%)$ at $50 \mathrm{mg}$. At $15 \mathrm{mg}, 30 \mathrm{mg}$ and $50 \mathrm{mg}$, gefapixant resulted in statistically significant improvements in awake cough frequency over placebo; reductions with $30 \mathrm{mg}$ and $50 \mathrm{mg}$ (mean \pm SD $-23.9 \pm 38.0$ events $\cdot \mathrm{h}^{-1}$ and $-24.3 \pm 35.5$ events $\cdot \mathrm{h}^{-1}$, respectively) were similar to those seen with $50 \mathrm{mg}$ gefapixant in study $1\left(-26.5 \pm 37.8\right.$ events $\left.\cdot \mathrm{h}^{-1}\right)$, suggesting that $30 \mathrm{mg}$ was the lowest fully active dose on the last $24 \mathrm{~h}$ of a 4 -day dosing period. Patients with the highest baseline cough frequency experienced the greatest improvements with gefapixant; absolute changes in awake cough frequency negatively correlated with baseline awake cough frequency (e.g. gefapixant $50 \mathrm{mg}$ study 1 Spearman correlation $\mathrm{r}=-0.72, \mathrm{p}<0.001$, and study $2 \mathrm{r}=-0.75, \mathrm{p}<0.001)$.

No statistically significant differences in cough frequency with gefapixant versus placebo were found during sleep due to the low frequency and high variability of cough. Over the full 24-h monitoring period, significant improvements over placebo occurred for all doses $\geqslant 30 \mathrm{mg}$ (figure $2 \mathrm{c}$ and $\mathrm{d}$ ).

\section{Cough severity VAS}

As dose increased from 50 to $200 \mathrm{mg}$ in study 1, the cough severity VAS improved incrementally, but statistically significant differences from placebo only occurred at $\geqslant 100 \mathrm{mg}$, higher doses than for cough monitoring (figure 2e). Significant changes for gefapixant over placebo were mean (95\% CI)

\begin{tabular}{lcc} 
TABLE 1 Patient characteristics & & \\
& Study $\mathbf{1}$ & Study 2 \\
\hline Subjects & 29 & 30 \\
Age years & $63.2 \pm 7.35$ & $60.2 \pm 11.06$ \\
Male:female & $4: 25$ & $6: 24$ \\
Race & $1(3.4)$ & $1(3.3)$ \\
$\quad$ Asian & $0(0)$ & $1(3.3)$ \\
$\quad$ Black or African-American & $28(96.6)$ & $28(93.3)$ \\
$\quad$ White & $26.6 \pm 4.82$ & $26.5 \pm 4.82$ \\
BMI $\mathbf{~ k g} \cdot \mathbf{m}^{-\mathbf{2}}$ & $15.4(1.4-55.3)$ & $13.2(1.9-42.8)$ \\
Cough duration years & $77.0(67-102)$ & $82.0(69-111)$ \\
FEV $\mathbf{1}$ /FVC ratio \%
\end{tabular}

Data are presented as $\mathrm{n}$, mean $\pm \mathrm{SD}, \mathrm{n}(\%)$ or median (range). BMI: body mass index; $\mathrm{FEV}_{1}$ : forced expiratory volume in $1 \mathrm{~s}$; FVC: forced vital capacity. 
TABLE 2 Efficacy end-points for gefapixant compared to matched placebo in studies 1 and 2

Study 1

Study 2

\begin{tabular}{|c|c|c|c|c|c|c|c|c|c|c|c|c|c|c|c|c|c|c|c|}
\hline \multicolumn{5}{|c|}{ Gefapixant } & \multicolumn{5}{|c|}{ Placebo } & \multicolumn{5}{|c|}{ Gefapixant } & \multicolumn{5}{|c|}{ Placebo } \\
\hline $\begin{array}{c}\text { Day } 0 \\
\text { Baseline }\end{array}$ & $\begin{array}{l}\text { Day } 4 \\
50 \mathrm{mg}\end{array}$ & $\begin{array}{c}\text { Day } 8 \\
100 \mathrm{mg}\end{array}$ & $\begin{array}{l}\text { Day } 12 \\
150 \mathrm{mg}\end{array}$ & $\begin{array}{l}\text { Day } 16 \\
200 \mathrm{mg}\end{array}$ & $\begin{array}{c}\text { Day } 0 \\
\text { Baseline }\end{array}$ & $\begin{array}{c}\text { Day } 4 \\
\text { Placebo }\end{array}$ & $\begin{array}{c}\text { Day } 8 \\
\text { Placebo }\end{array}$ & $\begin{array}{l}\text { Day } 12 \\
\text { Placebo }\end{array}$ & $\begin{array}{l}\text { Day } 16 \\
\text { Placebo }\end{array}$ & $\begin{array}{c}\text { Day } 0 \\
\text { Baseline }\end{array}$ & $\begin{array}{c}\text { Day } 4 \\
7.5 \mathrm{mg}\end{array}$ & $\begin{array}{l}\text { Day } 8 \\
15 \mathrm{mg}\end{array}$ & $\begin{array}{l}\text { Day } 12 \\
30 \mathrm{mg}\end{array}$ & $\begin{array}{l}\text { Day } 16 \\
50 \mathrm{mg}\end{array}$ & $\begin{array}{c}\text { Day 0 } \\
\text { Baseline }\end{array}$ & $\begin{array}{c}\text { Day } 4 \\
\text { Placebo }\end{array}$ & $\begin{array}{c}\text { Day } 8 \\
\text { Placebo }\end{array}$ & $\begin{array}{l}\text { Day } 12 \\
\text { Placebo }\end{array}$ & $\begin{array}{l}\text { Day } 16 \\
\text { Placebo }\end{array}$ \\
\hline
\end{tabular}

\begin{tabular}{|c|c|c|c|c|c|c|c|c|c|c|c|c|c|c|c|c|c|c|c|c|}
\hline $\begin{array}{c}\text { Awake cough } \\
\text { frequency } \\
\text { events }^{-1}\end{array}$ & $\begin{array}{c}54.5 \\
\pm 41.1 \\
(41.3)\end{array}$ & $\begin{array}{c}29.9 \\
\pm 22.5^{*} \\
(22.7)\end{array}$ & $\begin{array}{c}25.7 \\
\pm 19.1 * \\
(18.2)\end{array}$ & $\begin{array}{c}26.0 \\
\pm 17.9 * \\
(18.7)\end{array}$ & $\begin{array}{c}28.0 \\
\pm 23.8^{*} \\
(18.7)\end{array}$ & $\begin{array}{c}52.8 \\
\pm 40.4 \\
(38.2)\end{array}$ & $\begin{array}{l}51.1 \\
\pm 39.5 \\
(36.0)\end{array}$ & $\begin{array}{c}51.0 \\
\pm 39.1 \\
(36.2)\end{array}$ & $\begin{array}{l}56.0 \\
\pm 48.7 \\
(35.2)\end{array}$ & $\begin{array}{l}54.0 \\
\pm 39.3 \\
(39.5)\end{array}$ & $\begin{array}{l}49.6 \\
\pm 44.0 \\
(24.6)\end{array}$ & $\begin{array}{l}39.3 \\
\pm 36.0 \\
(19.7)\end{array}$ & $\begin{array}{c}34.8 \\
\pm 31.4 * \\
(16.8)\end{array}$ & $\begin{array}{c}26.8 \\
\pm 26.3^{*} \\
(13.4)\end{array}$ & $\begin{array}{c}27.0 \\
\pm 27.4^{*} \\
(12.1)\end{array}$ & $\begin{array}{c}46.1 \\
\pm 39.8 \\
(27.7)\end{array}$ & $\begin{array}{c}44.8 \\
\pm 34.9 \\
(31.2)\end{array}$ & $\begin{array}{c}41.4 \\
\pm 33.3 \\
(24.5)\end{array}$ & $\begin{array}{c}48.2 \\
\pm 42.4 \\
(22.8)\end{array}$ & $\begin{array}{l}50.6 \\
\pm 34.4 \\
(35.8)\end{array}$ \\
\hline $\begin{array}{l}\text { Night cough } \\
\text { frequency } \\
\text { events.h }{ }^{-1}\end{array}$ & $8.3 \pm 9.3$ & $\begin{array}{l}4.8 \\
\pm 6.6\end{array}$ & $4.6 \pm 8.9$ & $5.5 \pm 6.7$ & $4.3 \pm 6.4$ & $8.3 \pm 9.3$ & $\begin{array}{c}8.5 \\
\pm 10.4\end{array}$ & $7.5 \pm 9.9$ & $\begin{array}{c}10.1 \\
\pm 13.2\end{array}$ & $\begin{array}{c}8.3 \\
\pm 10.6\end{array}$ & $\begin{array}{r}10.1 \\
\pm 26.8\end{array}$ & $\begin{array}{c}8.9 \\
\pm 12.3\end{array}$ & $\begin{array}{c}5.5 \\
\pm 7.9\end{array}$ & $6.2 \pm 8.4$ & $\begin{array}{c}5.6 \\
\pm 10.0\end{array}$ & $5.6 \pm 7.6$ & $7.0 \pm 9.5$ & $5.0 \pm 7.4$ & $5.8 \pm 7.8$ & $\begin{array}{c}10.1 \\
\pm 18.4\end{array}$ \\
\hline $\begin{array}{l}\text { 24-h cough } \\
\text { frequency } \\
\text { events } \cdot h^{-1}\end{array}$ & $\begin{array}{r}39.7 \\
\pm 28.4\end{array}$ & $\begin{array}{c}22.7 \\
\pm 17.0^{*}\end{array}$ & $\begin{array}{c}20.4 \\
\pm 16.4^{*}\end{array}$ & $\begin{array}{c}19.9 \\
\pm 13.7 *\end{array}$ & $\begin{array}{c}21.3 \\
\pm 18.0^{*}\end{array}$ & $\begin{array}{c}37.9 \\
\pm 27.5\end{array}$ & $\begin{array}{c}37.5 \\
\pm 27.8\end{array}$ & $\begin{array}{r}37.7 \\
\pm 27.2\end{array}$ & $\begin{array}{r}41.3 \\
\pm 34.6\end{array}$ & $\begin{array}{l}40.6 \\
\pm 28.4\end{array}$ & $\begin{array}{r}36.3 \\
\pm 32.3\end{array}$ & $\begin{array}{l}29.1 \\
\pm 25.7\end{array}$ & $\begin{array}{r}24.8 \\
\pm 21.9\end{array}$ & $\begin{array}{c}19.5 \\
\pm 17.6 *\end{array}$ & $\begin{array}{c}20.8 \\
\pm 20.5^{*}\end{array}$ & $\begin{array}{c}32.2 \\
\pm 28.0\end{array}$ & $\begin{array}{r}31.5 \\
\pm 23.8\end{array}$ & $\begin{array}{c}29.4 \\
\pm 23.3\end{array}$ & $\begin{array}{r}34.5 \\
\pm 30.8\end{array}$ & $\begin{array}{r}37.3 \\
\pm 25.9\end{array}$ \\
\hline $\begin{array}{l}\text { Cough severity } \\
\text { VAS mm }\end{array}$ & $\begin{array}{c}58.4 \\
\pm 18.7\end{array}$ & $\begin{array}{r}45.0 \\
\pm 25.3\end{array}$ & $\begin{array}{c}33.2 \\
\pm 25.6 *\end{array}$ & $\begin{array}{c}30.6 \\
\pm 26.1 *\end{array}$ & $\begin{array}{c}28.0 \\
\pm 26.2^{*}\end{array}$ & $\begin{array}{c}52.2 \\
\pm 19.2\end{array}$ & $\begin{array}{c}48.4 \\
\pm 20.8\end{array}$ & $\begin{array}{c}46.9 \\
\pm 21.2\end{array}$ & $\begin{array}{c}50.8 \\
\pm 24.0\end{array}$ & $\begin{array}{c}55.6 \\
\pm 24.1\end{array}$ & $\begin{array}{c}54.5 \\
\pm 24.3\end{array}$ & $\begin{array}{l}41.8 \\
\pm 26.2\end{array}$ & $\begin{array}{c}37.1 \\
\pm 26.8\end{array}$ & $\begin{array}{c}31.2 \\
\pm 23.3^{*}\end{array}$ & $\begin{array}{c}30.4 \\
\pm 25.3^{*}\end{array}$ & $\begin{array}{c}57.2 \\
\pm 23.7\end{array}$ & $\begin{array}{c}50.9 \\
\pm 24.3\end{array}$ & $\begin{array}{c}47.3 \\
\pm 26.3\end{array}$ & $\begin{array}{c}49.5 \\
\pm 24.7\end{array}$ & $\begin{array}{l}48.0 \\
\pm 27.0\end{array}$ \\
\hline $\begin{array}{l}\text { Cough severity } \\
\text { diary }\end{array}$ & $4.2 \pm 1.9$ & $\begin{array}{c}3.6 \\
\pm 1.9\end{array}$ & $\begin{array}{c}3.1 \\
\pm 1.9 *\end{array}$ & $\begin{array}{c}2.6 \\
\pm 1.8^{*}\end{array}$ & $\begin{array}{c}2.6 \\
\pm 2.0 *\end{array}$ & $3.7 \pm 1.6$ & $3.6 \pm 1.9$ & $3.8 \pm 1.9$ & $3.8 \pm 1.8$ & $3.8 \pm 2.0$ & $4.5 \pm 2.0$ & $\begin{array}{l}3.6 \\
\pm 2.1\end{array}$ & $\begin{array}{c}3.3 \\
\pm 2.1^{*}\end{array}$ & $\begin{array}{c}2.9 \\
\pm 1.9 *\end{array}$ & $\begin{array}{c}3.0 \\
\pm 2.2^{*}\end{array}$ & $4.5 \pm 1.9$ & $4.1 \pm 1.9$ & $4.0 \pm 2.0$ & $4.0 \pm 1.7$ & $3.8 \pm 1.7$ \\
\hline $\begin{array}{l}\text { Total LCQ } \\
\text { score }\end{array}$ & $12.3 \pm 3.1$ & & & & $\begin{array}{c}15.4 \\
\pm 4.2^{*}\end{array}$ & $13.1 \pm 3.4$ & & & & $\begin{array}{l}12.3 \\
\pm 3.4\end{array}$ & $12.6 \pm 4.0$ & & & & $\begin{array}{c}16.2 \\
\pm 4.1^{*}\end{array}$ & $13.3 \pm 3.8$ & & & & $\begin{array}{l}13.4 \\
\pm 3.9\end{array}$ \\
\hline
\end{tabular}

Data are presented as arithmetic mean \pm SD (geometric mean). Bold type represents statistical significance. VAS: visual analogue scale; LCQ: Leicester Cough Questionnaire. *: $\mathrm{p}<0.05$ for analysis of change from baseline for gefapixant compared with placebo. 


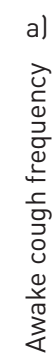

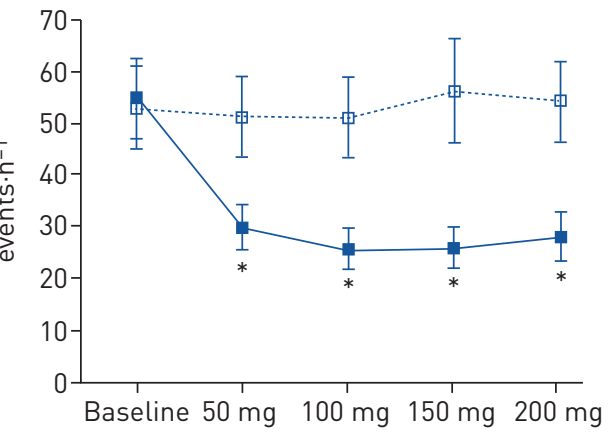
Gefapixant/matched placebo
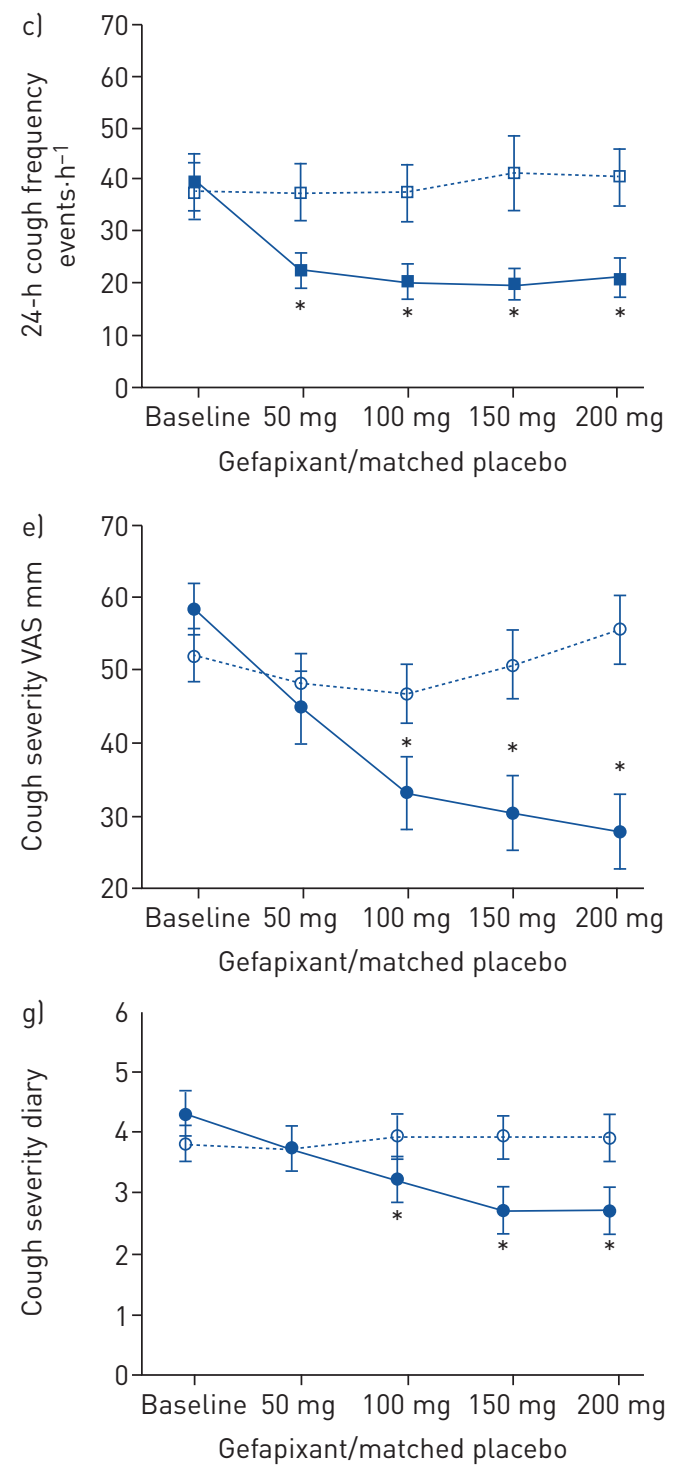
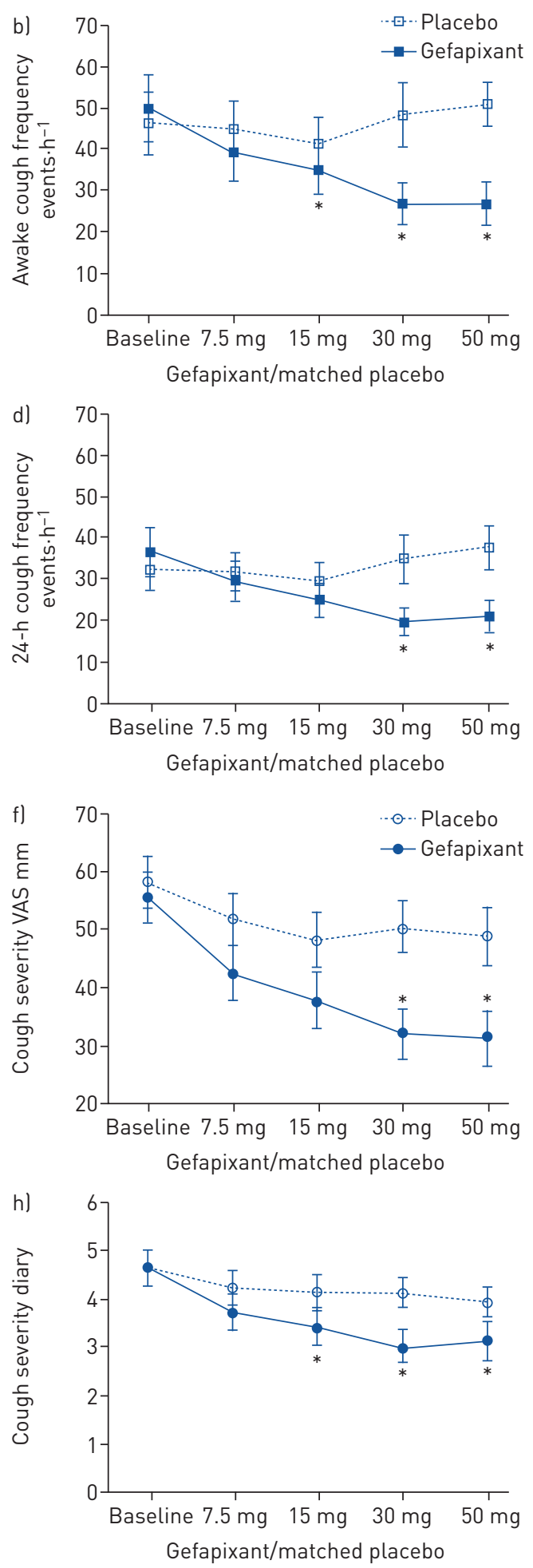

FIGURE 2 Efficacy outcome measures for studies 1 and 2. Data are shown as arithmetic mean \pm SEM with open symbols representing placebo and closed symbols gefapixant treatment. Objective cough frequency during waking hours was the primary end-point a) study 1, b) study 2, plotted for baseline and increasing doses of gefapixant or matched placebo. Cough frequency over the $24-\mathrm{h}$ monitoring period is shown in c) study 1 and d) study 2. Patient-reported outcomes of cough severity visual analogue scale (VAS) in e) study 1 and f) study 2 and the cough severity diary in g) study 1 and h) study 2. Note that the y-axis for cough severity VAS does not start at zero. ${ }^{*}$ : $p<0.05$ compared with placebo. 
$-20.0(-33.6--6.3) \mathrm{mm}$ at $100 \mathrm{mg},-26.1(-40.7--11.6) \mathrm{mm}$ at $150 \mathrm{mg}$ and $-33.8(-48.4--19.1) \mathrm{mm}$ at $200 \mathrm{mg}$. In study 2, cough severity VAS improved in a similar manner from $7.5 \mathrm{mg}$ to $50 \mathrm{mg}$, with significant improvements over placebo at $30 \mathrm{mg}(-15.6,-27.6--3.6 \mathrm{~mm})$ and $50 \mathrm{mg}(-15.4,-30.4--0.5 \mathrm{~mm})$ (figure 2f). Of note, gefapixant $50 \mathrm{mg}$ significantly improved cough severity VAS in study 2 (when administered for the last 4 days), but not in study 1 (when administered for the first 4 days).

Cough severity diary

The cough severity diary showed a comparable pattern of responses to the cough severity VAS (figure $2 \mathrm{~g}$ and $\mathrm{h}$ ), with incremental improvements as gefapixant dose increased and significant differences from placebo at $\geqslant 100 \mathrm{mg}$ in study 1 and $\geqslant 15 \mathrm{mg}$ in study 2 .

$\angle C Q$

The total LCQ scores displayed statistically significant improvements over placebo after 16 days of gefapixant treatment in both studies (table 2); the differences from baseline exceeded the minimal clinically important difference of 1.3 .

\section{Safety and tolerability assessments}

In study 1 , there were two subjects with serious adverse events: one subject had a vasovagal response with increased serum creatinine and was diagnosed with acute tubular necrosis while on active treatment (the subject discontinued the study and recovered fully); another subject was diagnosed with invasive ductal breast carcinoma while on placebo (the subject required surgery and radiation, but completed the study). In study 2, one subject had a serious adverse event of cerebrovascular accident (the subject discontinued the study). In study 1, three subjects discontinued the study (due to taste effect, dyspepsia, vertigo and oral paraesthesia in one subject on active treatment, acute tubular necrosis on active treatment and intolerable gastro-oesophageal reflux disease on placebo). In study 2, one subject discontinued due to sinusitis and jaw abscess while receiving gefapixant $50 \mathrm{mg}$. There were no deaths in these studies (table 3 ).

Taste disturbances (ageusia, dysgeusia or hypogeusia) were most common, with one subject discontinuing gefapixant $(50 \mathrm{mg}$ ) as a consequence (study 1). Taste disturbances were dose-related, occurring in the majority of patients at the highest doses $(150$ and $200 \mathrm{mg}$ ) and substantially reducing in study 2 (table 3 ). Notably, anti-tussive effects displayed a different relationship with gefapixant dose and only began to reduce at doses $<30 \mathrm{mg}$. In order to evaluate the relationship between taste disturbance and anti-tussive effects, a post hoc analysis was undertaken for patients who had taste disturbance (yes or no) and efficacy level; results of this analysis demonstrated that those patients who had taste disturbance did have numerically greater anti-tussive effects, but the difference in efficacy was not large and was not statistically significant (supplementary figure S1).

\section{Discussion}

The results of these studies both corroborate and expand upon those reported in the first study of gefapixant [14], now demonstrating that anti-tussive effects can be achieved at a fraction of the original $600 \mathrm{mg}$ twice-daily dose tested. The average percentage improvements in cough frequency from baseline over placebo were not as high as previously attained; however, these studies were designed to assess the relationship between dose, efficacy and tolerability, rather than precisely estimate effect sizes, as can be appreciated from the confidence intervals. Participants in these studies were typical of those presenting with refractory chronic cough, being predominantly female and aged 50-70 years [19]. Selection of those with a cough severity VAS $>40 \mathrm{~mm}$ enriched the studies with subjects with higher cough burden, to facilitate the appreciation of dose-response relationships. Furthermore, as previously observed, patients with the highest baseline cough frequency experienced greater improvements in cough with gefapixant treatment. Moreover, improvements in objective cough frequency were accompanied by significant improvements in patient-reported cough severity and impact upon quality of life, and changes in these correlated well with percentage/absolute improvements in cough frequency.

Of note, there was a lag in improvements in cough VAS/cough severity diary compared with objective cough frequency in study 1 . After 4 days' treatment at $50 \mathrm{mg}$ twice daily, patient-reported outcomes suggested gefapixant was no better than placebo, contrary to cough frequency measurements showing an improvement equivalent to higher doses. We speculate that the short duration of each dosing period may explain this finding. 4 days' therapy may be insufficient for patients to be confident of a true amelioration of their cough, rather than part of usual day-to-day variability. This notion is substantiated by comparing the same $(50 \mathrm{mg}$ ) dose in study 2 , where a similar improvement in cough frequency was now accompanied by VAS/cough severity diary scores improved to a degree seen at higher doses in study 1 . Thus, in study 2 , $50 \mathrm{mg}$ twice daily was administered last and scores were completed after patients had experienced 8 days of significantly reduced cough frequency. These observations reveal the importance of context for 
TABLE 3 Summary of safety and tolerability

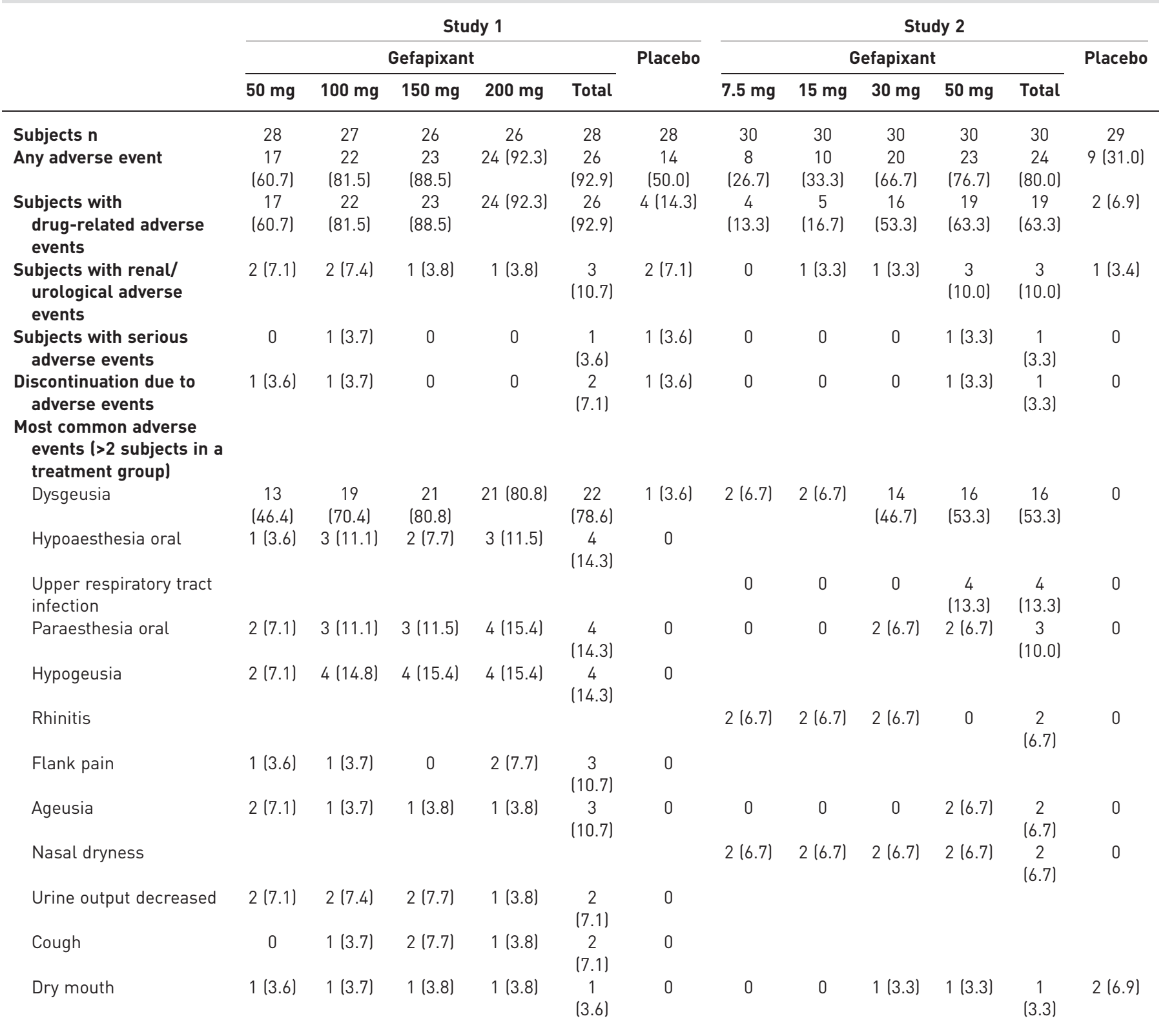

Data are presented as $\mathrm{n}(\%)$, unless otherwise stated.

patient-reported outcomes measuring cough and underline the importance of objective measurements as the most sensitive index in determining optimal dosing of anti-tussive agents.

Serious adverse events were rare in this study and no deaths occurred. The majority of adverse events were related to tolerability, specifically the taste adverse event of dysgeusia. Notably, discontinuations were rare, with only one subject experiencing a taste adverse event withdrawing from the study. Taste effects were largely dose-related. Our results demonstrate that gefapixant $\geqslant 30 \mathrm{mg}$ produces maximal reductions in objective cough frequency. In contrast, effects on taste acuity exhibited a quite different relationship to gefapixant dose, with reductions in the proportion of patients experiencing altered taste at doses $<150 \mathrm{mg}$. The improved tolerability at doses that retain anti-tussive efficacy confirms gefapixant as a promising anti-tussive therapy. Additionally, the anti-tussive effect among those who experience a taste effect and those who do not were not significantly different.

All studies have limitations, and we are motivated to consider these within our studies. This was a study to evaluate the therapeutic dose range of gefapixant that included a limited sample size and limited treatment 
period with each dose before escalation; therefore, the sample size was relatively small and further research with longer-term exposure in a larger patient sample will be needed to better evaluate gefapixant in patients with refractory chronic cough; phase 3 studies are currently ongoing. Additionally, it is difficult to estimate the influence of unblinding of study treatment due to taste disturbances; improvements in objective cough frequency in patients reporting reduced taste acuity were greater than those not experiencing that side-effect, suggesting that unblinding could be an issue. Furthermore, there was a change in the formulation of gefapixant and increase in the washout period in the second study; however, the efficacy of the $50 \mathrm{mg}$ dose is extremely similar in the two studies, suggesting that these differences had very little impact on the findings. Of note, we did not formally assess taste in this study, e.g. taste strip testing. To include a specific evaluation of taste would have increased the burden for patients, but also carried the risk of artificially increasing the reporting of taste adverse events by increasing patient awareness and vigilance of these.

In summary, at doses markedly lower than tested previously in a proof-of-concept study, P2X3 antagonism with gefapixant reduced objective cough frequency, improved reported cough severity and quality of life and was associated with improved tolerability in patients with refractory chronic cough. This study both highlights the importance of objective assessments of efficacy in the optimal development of cough therapies and suggests that gefapixant shows promise as an efficacious novel therapy. Further studies examining longer-term anti-tussive benefit and potential for resetting of cough sensitisation are currently underway.

Acknowledgements: Medical writing and editorial support was provided by Anish Mehta (Merck and Co., Inc., Kenilworth, NJ, USA). Submission assistance was provided by Jennifer Pawlowski (Merck and Co., Inc.). The authors would like to thank the recruiting principal investigators and institutions: Mandel Sher (Center for Cough, Largo, FL, USA), Warner Carr (Allergy and Asthma Associates of Southern California, Mission Viejo, CA, USA), Alan Goldsobel (Allergy and Asthma Associates of Santa Clara Valley Research Center, San Jose, CA, USA), Gary Gross (Pharmaceutical Research \& Consulting Inc., Dallas, TX, USA), Wayne Harper (Wake Research Associates, Raleigh, NC, USA), John Holcomb (Diagnostics Research Group, San Antonio, TX, USA), Iftikhar Hussain (Vital Prospects Clinical Research Institute, Tulsa, OK, USA), Kevin Parks (Clinical Research Institute of Southern Oregon, Medford, OR, USA), Selwyn Spangenthal (American Health Research, Inc., Charlotte, NC, USA) and William Storms (Storms Clinical Research Institute, Colorado Springs, CO, USA).

Author contributions: J.A. Smith: conception, design or planning of the study, analysis of data, interpretation of results, drafting of the manuscript, critical review and revision of the manuscript. M.M. Kitt: conception, design or planning of the study, analysis of data, interpretation of results, critical review and revision of the manuscript. P. Butera: conception, design or planning of the study, acquisition of data, critical review and revision of the manuscript. S.A. Smith: analysis of data, critical review and revision of the manuscript. Y. Li: analysis of data, interpretation of results, critical review and revision of the manuscript. Z.J. Xu: analysis of data, critical review and revision of the manuscript. K. Holt: analysis of data, critical review and revision of the manuscript. S. Sen: analysis of data, drafting of the manuscript. M.R. Sher: acquisition of data, interpretation of results, critical review and revision of the manuscript. A.P. Ford: conception, design or planning of the study, interpretation of results, drafting of the manuscript, critical review and revision of the manuscript.

Conflict of interest: J.A. Smith reports research grants and personal fees for consultancy and advisory board work from Merck Inc., during the conduct of the study; research grants and personal fees for consultancy and advisory board work from GlaxoSmithKline, research grants and personal fees for consultancy from NeRRe Pharmaceuticals, Menlo, Bayer and Axalbion, personal fees for consultancy from Boehringer Ingleheim, Genentech, Neomed, Chiesi, Bellus and AstraZeneca, non-financial support (equipment provision) from Vitalograph, research grants from Afferent, outside the submitted work; in addition, has a patent "A method for generating output data" licensed. M.M. Kitt was an employee of Merck/Afferent, during the conduct of the study. P. Butera was an employee of Afferent Pharmaceuticals, Inc., during the conduct of the study. S.A. Smith reports personal fees for consultancy from Afferent Pharmaceuticals, during the conduct of the study. Y. Li reports personal fees for statistical work from Afferent/Merck and Co., Inc, during the conduct of the study. Z.J Xu has nothing to disclose. K. Holt has nothing to disclose. S. Sen has nothing to disclose. M. R. Sher reports personal fees from Afferent and Merck, during the conduct of the study; and is consultant to Bellus, Bayer, NeRRe with clinical studies with Menlo and NeRRe. A.P. Ford was an employee of Merck/Afferent, during the conduct of the study.

Support statement: This study was supported by funding from Afferent Pharmaceuticals Inc., which was acquired by Merck Sharp and Dohme Corp., a subsidiary of Merck and Co., Inc., Kenilworth, NJ, USA. J.A. Smith is funded by the Manchester Biomedical Research Centre, a Wellcome Investigator award and is an NIHR Senior Investigator. Funding information for this article has been deposited with the Crossref Funder Registry.

\section{References}

1 Consumer Healthcare Products Association. OTC Sales by Category 2012-2015. 2016. www.chpa.org/ OTCsCategory.aspx Date last accessed: June 6, 2016.

2 Smith SM, Schroeder K, Fahey T. Over-the-counter (OTC) medications for acute cough in children and adults in community settings. Cochrane Database Syst Rev 2014; 11: CD001831.

3 Monitoring the Future. National Survey Results on Drug Use, 1975-2015. Institute for Social Research, University of Michigan, 2015. http://monitoringthefuture.org/pubs.html\#monographs Date last accessed August 16, 2016. 
Cooper RJ. Over-the-counter medicine abuse - a review of the literature. J Subst Use 2013; 18: 82-107.

Rimsza ME, Newberry S. Unexpected infant deaths associated with use of cough and cold medications. Pediatrics 2008; 122: e318-e322.

6 Kelsall A, Decalmer S, McGuinness K, et al. Sex differences and predictors of objective cough frequency in chronic cough. Thorax 2009; 64: 393-398.

7 French CL, Irwin RS, Curley FJ, et al. Impact of chronic cough on quality of life. Arch Intern Med 1998; 158: 1657-1661.

8 Chen CC, Akopian AN, Sivilotti L, et al. A P2X purinoceptor expressed by a subset of sensory neurons. Nature 1995; 377: 428-431.

9 Basoglu OK, Barnes PJ, Kharitonov SA, et al. Effects of aerosolized adenosine $5^{\prime}$-triphosphate in smokers and patients with COPD. Chest 2015; 148: 430-435.

10 Basoglu OK, Pelleg A, Essilfie-Quaye S, et al. Effects of aerosolized adenosine $5^{\prime}$-triphosphate vs adenosine 5 '-monophosphate on dyspnea and airway caliber in healthy nonsmokers and patients with asthma. Chest 2005; 128: 1905-1909.

11 Fowles HE, Rowland T, Wright C, et al. Tussive challenge with ATP and AMP: does it reveal cough hypersensitivity? Eur Respir J 2017; 49: 1601452.

12 Kamei J, Takahashi Y. Involvement of ionotropic purinergic receptors in the histamine-induced enhancement of the cough reflex sensitivity in guinea pigs. Eur J Pharmacol 2006; 547: 160-164.

13 Kamei J, Takahashi Y, Yoshikawa Y, et al. Involvement of P2X receptor subtypes in ATP-induced enhancement of the cough reflex sensitivity. Eur J Pharmacol 2005; 528: 158-161.

14 Abdulqawi R, Dockry R, Holt $\mathrm{K}$, et al. P2X3 receptor antagonist (AF-219) in refractory chronic cough: a randomised, double-blind, placebo-controlled phase 2 study. Lancet 2015; 385: 1198-1205.

15 Pratter MR, Brightling CE, Boulet LP, et al. An empiric integrative approach to the management of cough: ACCP evidence-based clinical practice guidelines. Chest 2006; 129: 222S-231S.

16 Mitra A, Kesisoglou F. Impaired drug absorption due to high stomach pH: a review of strategies for mitigation of such effect to enable pharmaceutical product development. Mol Pharm 2013; 10: 3970-3979.

17 Vernon M, Kline Leidy N, Nacson A, et al. Measuring cough severity: development and pilot testing of a new seven-item cough severity patient-reported outcome measure. Ther Adv Respir Dis 2010; 4: 199-208.

18 Birring SS, Prudon B, Carr AJ, et al. Development of a symptom specific health status measure for patients with chronic cough: Leicester Cough Questionnaire (LCQ). Thorax 2003; 58: 339-343.

19 Morice AH, Jakes AD, Faruqi S, et al. A worldwide survey of chronic cough: a manifestation of enhanced somatosensory response. Eur Respir J 2014; 44: 1149-1155. 